\title{
Acute fatty liver of pregnancy
}

INSERM

\section{Source}

INSERM. (1999). Orphanet: an online rare disease and orphan drug data base. Acute fatty liver of pregnancy. ORPHA:243367

Acute fatty liver of pregnancy is a rare but severe complication occurring in the third trimester of pregnancy or in early postpartum period bearing a risk for perinatal and maternal mortality and characterized by jaundice, rise of hepatic injuries and evolving to acute liver failure and encephalopathy. 